\title{
Effects of Sucrose and Kangaroo Care on Pain Alleviation Among Preterm Neonates Undergoing Invasive Procedures
}

\author{
Azza A. Ghoneim \\ Department of Pediatric Nursing, Faculty of Nursing, Menoufia University, Shebin El-Kom, Egypt \\ Email address: \\ a_ghoneim@ut.edu.sa

\section{To cite this article:} \\ Azza A. Ghoneim. Effects of Sucrose and Kangaroo Care on Pain Alleviation Among Preterm Neonates Undergoing Invasive Procedures. \\ American Journal of Nursing Science. Vol. 5, No. 4, 2016, pp. 146-151. doi: 10.11648/j.ajns.20160504.14
}

Received: June 22, 2016; Accepted: July 1, 2016; Published: July 28, 2016

\begin{abstract}
Background: Persistent neonatal pain due to numerous painful procedures can result in serious consequences of the newborn. Effective pain management is required to promote physiologic stability and positive developmental outcomes in preterm infants. Aims of this study were to examine the effect of sucrose and kangaroo care on pain alleviation among preterm neonates undergoing invasive procedures and compare between sucrose versus kangaroo care on pain alleviation among preterm neonates undergoing invasive procedures. It hypothesized that sucrose and kangaroo care would be effective measures to alleviate procedural pain. The Design of this study was quasi-experimental research design. A sample of 60 neonates was selected to carry out this study then they were randomized to receive (a) sucrose ( $n=20)$, (b) kangaroo care ( $n$ $=20)$, or $(c)$ routine care $(n=20)$. Setting of this study was health care center for neonates. Tool of this study was Premature Infant Pain Profile (PIPP) (Stevens et al., 1996). Results showed that there was significant difference in PIPP score among preterm neonates within the three groups at 30 seconds and 1 minute $\left(\mathrm{P}<0.001^{* *}\right)$. Mean PIPP scores for sucrose, kangaroo care and routine care were $8.1 \pm 3.22,9.76 \pm 3.04$ and $10.15 \pm 2.64$ respectively. Conclusion: sucrose is the most effective intervention for alleviation of procedural pain in neonates. Therefore, sucrose is a recommended analgesic for premature neonates.
\end{abstract}

Keywords: Preterm Neonates, Procedural Pain, Sucrose and Kangaroo Care

\section{Introduction}

Prematurity is a major health concern, with a range of 12.3-18.1 million were born preterm worldwide (Blencowe et al., 2012). In United States, 12\% of infants are born prematurely (Furdon et al., 2014). Hassanein (2011) indicated that in Egypt, 12-15.8\% of live neonates were low birth weight and about one third were premature. Moreover, Blencowe et al., (2012) reported that in Egypt, about 8100 preterm neonates died from the complication of prematurity.

The World Health Organization defines prematurity as babies born before 37 weeks from the first day of the last menstrual period. Recent data indicate that $>1$ in 10 babies born around the world in 2010 were premature and this translates to an estimated 15 million preterm births (Blencowe et al., 2012).

Premature neonates have many physiologic challenges when adapting to extra uterine environment due to functional limitations of immature organs (Furdon et al., 2014). Indeed, they are at greater risk for congenital defects, respiratory distress syndrome, feeding difficulty, severe infections, temperature instability, jaundice, delayed brain development and anemia of prematurity (Lawn et al., 2012). These limitations are subjecting premature neonates to frequent painful procedures whether diagnostic or therapeutic (Simons, Dijk, Anand et al, 2003).

Simons and colleagues (2003) found that infants born at 25-42 weeks gestation experienced an average of 14 painful procedures per day during the first 2 weeks of life. The most frequently performed procedures were nasal, endo-tracheal, and nasopharyngeal suctioning, heel stick, intravenous, and nasogastric tube insertions. Although, these procedures were reported to be moderately painful (Simons et al., 2003; Gibbins et al., 2006; Stevens et al., 2013) evidence shows that procedural pain is often poorly managed in neonatal period, and many painful procedures are performed without any pain relief (APA, 2000; Anand 2001; Anand 2007; 


\section{Carbajal 2008)}

However, untreated procedural pain in neonates can result in overwhelming stress, developmental delay, permanent neurological impairment and emotional disorders (Anand, 2000). Therefore, proper pain management for procedural pain in neonates is a necessity. Sucrose and kangaroo care have been shown to be efficacious in diminishing procedural pain in full term neonates. However, there is less evidence for their efficacy and safety in preterm neonates (Walden \& Gibbins, 2008).

As the primary focus of nursing care in neonatal intensive care unite (NICUs) is to save lives, prevent and/or minimize the occurrence of complications (Mc Grath \& Braescu, 2004) nurses must be a part of the interdisciplinary team that can establish an effective management plan (Hatifield, 2003).

For this reason, this study conducted to evaluate the effect of sucrose and kangaroo care on alleviating pain among preterm neonates undergoing invasive procedures.

\section{Aims of the Study}

This study aimed to evaluate and compare between the effect of sucrose and kangaroo care on pain alleviation among preterm neonates undergoing invasive procedures.

\section{Hypothesis}

Sucrose and kangaroo care would be effective measures to alleviate procedural pain among preterm neonates.

\section{Subjects and Method}

\subsection{Research Design}

A quasi-experimental research design used in carrying out the study.

\subsection{Setting}

The study carried out at El-Gameai El- Sharea for neonates at Shebin El-Koom city.

\subsection{Subjects: (Population and Sample)}

A purposive sample of 60 neonates who met the study criteria was selected. A simple random sample was used to assign them equally into three groups. Each group included 20 preterm neonates. Study group I orally administers sucrose, study group II received kangaroo care and group III received routine care. They selected based on the following criteria

i. Inclusion criteria:

- Newborn from birth to less than 28 days of life

- Preterm (from Gestational age from 28 weeks)

ii. Exclusion criteria:

- Mechanically ventilated neonates were excluded.

- Neonates with major congenital anomaly were excluded.

- Neonates being given CNS depressants and muscle relaxants were excluded.

- Neonates with hyperglycemia

\subsection{Data Collection Tools}

Two tools were utilized for data collection.

i. Tool one: Demographic characteristic structured questionnaire sheet, it developed by the researcher. It included data about neonate's sex, gestational age, postnatal age, diagnosis and type of invasive procedure (heel lancing, intravenous cannulation and immunization).

ii. Tool two: Premature Infant Pain Profile (PIPP). It is a behavioral measure of pain for premature infants developed by Stevens Johnston et al. (1996). It included seven indicators which are gestational age, behavioral state, change in heart rate, change in oxygen saturation, brow bulge, eye squeeze and naso-labial furrow.

- Scoring for premature infant pain profile $=$ SUM (points for all 7 indicators): minimum score $=0$ and maximum score $=21$. The higher the score, the greater the pain behavior.

\subsection{Methods of Data Collection}

i. Written permission:

Prior to data collection, an oral permission to carry out the study was obtained from the director of El-Gameai ElSharea after explaining the purpose of the study and methods of data collection.

ii. Tools development:

Tools developed and adopted by the researcher for data collection after an extensive review of relevant literature. For validity assurance purpose, tools submitted to a jury of five expertises in the field of pediatrics and pediatric nursing.

iii. Reliability:

Reliability of the tool was determined to assess the extent to which items in the tool were related to each other by Cronbach's co-efficiency alpha test $(\mathrm{r}=0.68)$.

iv. Protection of human rights:

For ethical considerations, an oral consent was obtained from parents to allow their preterm neonates share in the study. Therefore, the objectives of the study, its importance, safety and confidentiality were clarified.

v. Pilot study:

A pilot study was carried out on six infants $(10 \%$ of the sample) to test the practicability, applicability and timing of data collection. No necessary modification was done. Therefore, the sample of the pilot study included in the sample.

\subsection{Data Collection}

i. Data collected over a period of 6 months starting from March 2014 to August 2014.

ii. A simple random sample done to assign newborns into group I group II and group III.

iii. Base line data collected from the three groups about 
pain behavior using Premature Infant Pain Profile (PIPP).

iv. For the study group I, newborn infants received $1.0 \mathrm{ml}$ of $25 \%$ oral sucrose solution 2 minutes before heel lancing.

v. For the study group II, newborn infants received kangaroo care for 10-15 minutes before heel lancing. They wore only a diaper and positioned on skin-toskin contact with their mothers. After a 2-minute baseline period of monitoring, the heel lanced for blood sample collection.

vi. For the group III (control group), newborn infants received only routine hospital care.

vii. Premature neonates of groups I and II were evaluated for physiological and behavioral pain indicators at 30 seconds, 1, 3, and 5 minutes after heel lancing.

viii. Changes in heart rate and oxygen saturation $\left(\mathrm{SpO}_{2}\right)$ were calculated and tabulated.

\subsection{Data Analysis}

Data coded and transformed into specially designed form to be suitable for computer entry process. Data entered and analyzed by using SPSS (Statistical Package for Social Science) statistical package version 13. Graphics done using Excel program.

Quantitative data were presented by mean (X) and standard deviation (SD). It was analyzed using student $t$ test for comparison between two means and one way ANOVA for comparison between three means.

Qualitative data presented in the form of frequency distribution tables, number and percentage. It analyzed by chi-square $\left(\chi^{2}\right)$ test. However, if an expected value of any cell in the table was less than 5, Fisher Exact test was used. Level of significance was set as $\mathrm{P}$ value $<0.05$ for all significant statistical tests.

\section{Results}

Table 1. Distribution of the premature neonates regarding their characteristics.

\begin{tabular}{|c|c|c|c|c|c|c|c|c|}
\hline \multirow{2}{*}{$\begin{array}{l}\text { Characteristics } \\
\text { Sex }\end{array}$} & \multicolumn{2}{|c|}{ Group I $(n=20)$} & \multicolumn{2}{|c|}{ Group II $(n=20)$} & \multicolumn{2}{|c|}{ Group III $(n=20)$} & \multirow{2}{*}{$\mathbf{X}^{2}$} & \multirow{2}{*}{$\mathbf{P}$} \\
\hline & No & $\%$ & No & $\%$ & No & $\%$ & & \\
\hline Male & 14 & 70 & 11 & 55 & 10 & 50 & 1.78 & $0.41^{\mathrm{ns}}$ \\
\hline Female & 6 & 30 & 9 & 45 & 10 & 50 & & \\
\hline \multirow{2}{*}{ Gestational age } & \multirow{2}{*}{\multicolumn{2}{|c|}{$($ Mean \pm SD) }} & \multicolumn{2}{|c|}{$($ Mean \pm SD) } & \multicolumn{2}{|c|}{$($ Mean \pm SD $)$} & $\mathrm{F}$ & $\mathrm{P}$ \\
\hline & & & \multicolumn{2}{|c|}{$32.85 \pm 2.99$} & \multicolumn{2}{|c|}{$33.31 \pm 2.64$} & 0.63 & $0.53^{\mathrm{ns}}$ \\
\hline
\end{tabular}

${ }^{n s}$ non-significant

Table 1 clarifies the characteristics of the premature neonates. There were no statistical significant differences between neonates in sucrose, kangaroo and routine care groups regarding their mean gestational age $(33.8,32.85$, 33.31) respectively.

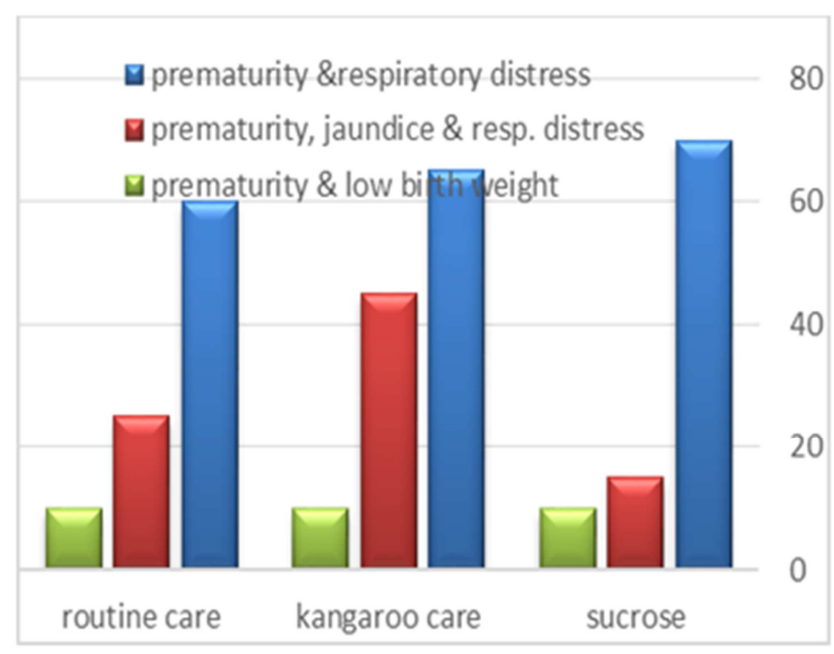

Figure 1. Distribution of the premature neonates regarding their diagnosis.

Figure 1 shows the distribution of premature neonates according to their diagnosis. It revealed that the majority of neonates $(70 \%, 65 \%$ and $60 \%)$ was premature and had respiratory distress syndrome.

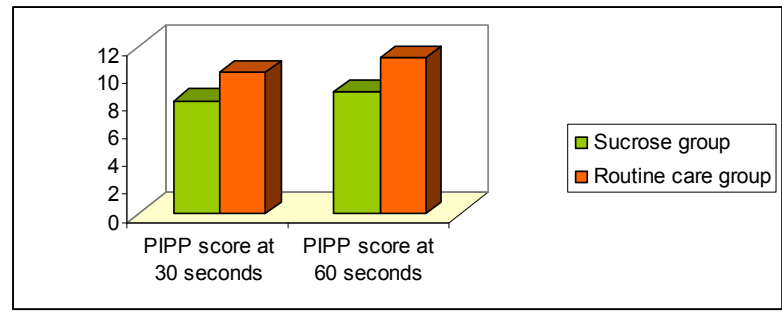

Figure 2. Pain score of neonates in sucrose and routine care groups at 30 and 60 seconds.

Figure 2 clarifies pain score of neonates in sucrose and routine care groups at 30 and 60 seconds. It was clear that pain scores in sucrose group were lower than routine care group at 30 and 60 seconds. Therefore, there were statistical significant differences at $1 \%$ level of statistical significance between sucrose and routine care groups.

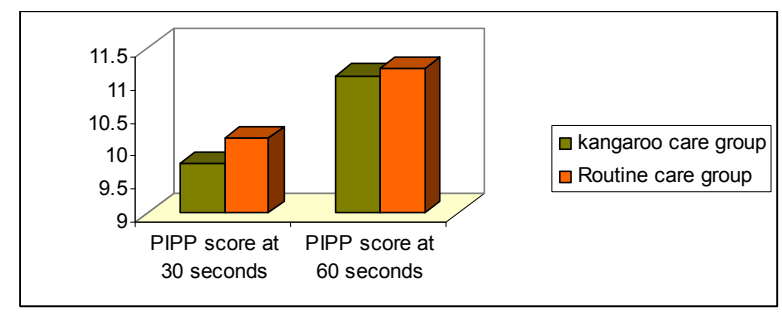

Figure 3. Pain score of neonates in kangaroo care and routine care groups at 30 and 60 seconds. 
Figure 3 shows pain score of neonates in kangaroo care and routine care groups at 30 and 60 seconds. There were no statistical significant differences between kangaroo care and routine care groups.

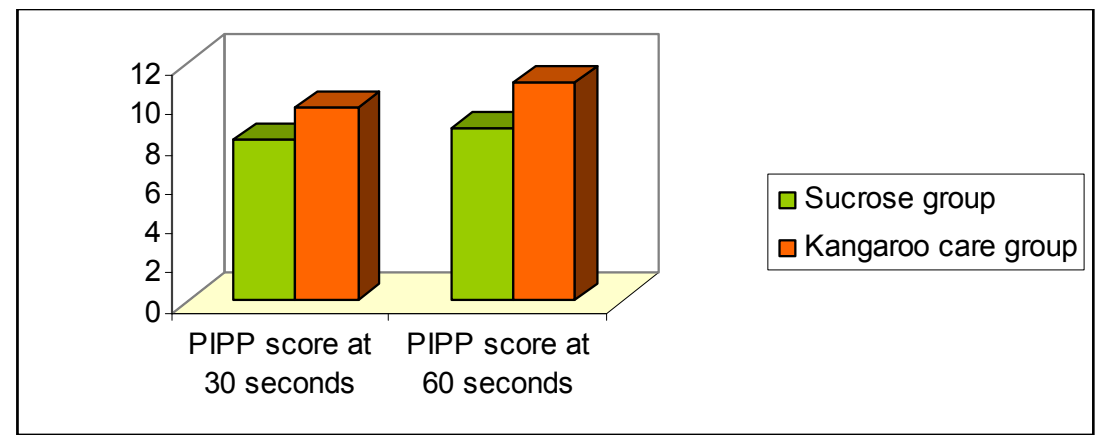

Figure 4. Pain score of neonates in sucrose and kangaroo care groups at 30 and 60 seconds.

Figure 4 clarifies pain score of neonates in sucrose and kangaroo care groups at 30 and 60 seconds. It was clear that pain scores in sucrose group were lower than kangaroo care group at 30 and 60 seconds. Therefore, there were statistical significant differences at $1 \%$ level of statistical significance between sucrose and kangaroo care groups.

Table 2. Pain score of premature neonates in sucrose, kangaroo care and routine care groups at 30 and 60 seconds.

\begin{tabular}{lllll}
\hline PIPP score & $\begin{array}{l}\text { Sucrose }(\mathbf{n}=\mathbf{2 0}) \\
\text { Mean } \pm \text { SD }\end{array}$ & $\begin{array}{l}\text { Kangaroo care }(\mathbf{n}=\mathbf{2 0}) \\
\text { Mean } \pm \text { SD }\end{array}$ & \multicolumn{2}{l}{$\begin{array}{l}\text { Routine care }(\mathbf{n}=\mathbf{2 0}) \\
\text { Mean } \pm \text { SD }\end{array}$} \\
\hline At 30 seconds & $8.1 \pm 3.22$ & $9.76 \pm 3.04$ & $10.15 \pm 2.64$ & 22.43 \\
At 60 seconds & $8.76 \pm 4.04$ & $11.10 \pm 3.23$ & $11.20 \pm 3.43$ \\
\hline
\end{tabular}

$\mathrm{P}$ value $<0.05 * *$ significant

Table 2 shows the mean pain scores of sucrose, kangaroo care as well as routine care groups. It revealed that premature neonates in the sucrose group showed lower pain score at 30 second and 1 minute $(8.1 \pm 3.22,8.76 \pm 4.04)$ than their peers in kangaroo and routine care groups $(9.76 \pm 3.04 ; 11.10 \pm 3.23$ and $10.15 \pm 2.64 ; 11.20 \pm 3.43)$ respectively. Therefore, there were statistical significant differences at $5 \%$ level of statistical significance between neonates in sucrose, kangaroo and routine care groups.

\section{Discussion}

Premature infant's survival creates critical needs for early intervention services to assist these infants to overcome the transient delays or permanent effects of their early neonatal experiences. (Allen, 2009). These delays or permanent effects could be resulted from untreated neonatal pain. Although pain perception in neonates has been proved, many painful procedures still conducted on newborns without proper pain management. Therefore, effective pain management is required to protect neonates against iatrogenic disorders.

Regarding gestational age, results of the present study showed that no statistical significant differences between sucrose, kangaroo care and routine care groups. This could reveal that premature neonates in the three groups had close levels of condition at the health-illness continuum.

In relation to number of neonates in the sucrose, kangaroo care and routine care groups according to their diagnosis, the present study revealed that the majority of neonates were premature with respiratory distress related to health problems. This could be due to decreased surfactant substance in lungs of premature neonates; it considered the primary cause of respiratory distress syndrome in premature neonates. Anand et al., (2009) who reported that respiratory distress syndrome was the most common health problem in premature neonates supported these findings.

Concerning PIPP pain score, the present study revealed that premature neonates administered sucrose showed lower pain scores at 30 and 60 seconds compared to premature neonates received only routine care.

These results were consistent with Johnston, (1999), Stevens, (1999), Gibbins, et. al. (2002), Slater, (2010) and Harrison et al. (2012) who reported that sucrose significantly lessen pain scores in premature neonates at 30 seconds. This indicates a quick recovery and return to baseline state that maintain the homeostasis of premature neonate.

In addition, Gibbins, et al (2002) and Acharya et al., (2004) reported safety and efficacy of sucrose for procedural pain relief.

On the other hand, the results of the present study illustrated that pain scores at 60 seconds was increased. It may related to the duration of squeezing the heel rather than inserting the lance itself. Some neonates required more squeeze time than others to obtain sufficient amount of blood for sampling.

Regarding PIPP pain score of the premature neonates received kangaroo care; the present study revealed that there were no statistical significant differences between kangaroo care and routine care groups. In addition, they had lower pain score than peers in sucrose group.

This may be related to mothers' ignorance about kangaroo care and its technique. They were afraid to handle and carry their sick baby in that way. Their worries may transferred to 
their infants that resulted in ineffective pain relief technique.

This reveal the need for conducting a prenatal educational program on kangaroo care and its benefits to increase the parents' awareness particularly mothers.

In contrast with Gray et al., (2000) who reported that skinto-skin contact between neonates and their mothers reduce pain reactions in neonates during heel lance. In addition, Firoozeh et al., (2007) concluded that kangaroo care given before injection seems to be effectively decrease pain from injection. Moreover, Johnston et al., (2008) concluded that Very preterm neonates appear to have endogenous mechanisms elicited through skin-to-skin maternal contact that decrease pain response, but not as powerfully as in older preterm neonates. The shorter recovery time in kangaroo mother care is clinically important in helping maintain homeostasis.

\section{Conclusion}

i. The findings of the current study revealed that sucrose effectively reduce pain scores in preterm neonates undergoing invasive procedures.

ii. Kangaroo care was ineffectively alleviate pain in preterm neonates undergoing invasive procedures.

\section{Recommendations}

i. Nurses in NICUs should include sucrose as a pain relief measure for preterm infants undergoing invasive procedures.

ii. Written booklets, posters and videos should be available in each NICU in hospital to acknowledge mothers as well as nurses about kangaroo care.

iii. Further study is required to determine the effect of kangaroo care on pain and consider a prenatal educational program for mothers regarding kangaroo care.

\section{References}

[1] Stevens B, Johnston C, Petryshen P, Taddio A. Premature infant pain profile: development and initial validation. Clin J Pain. 1996; 12: 13-22.

[2] Blencowe H, Cousens S, Oestergaard MZ, Chou D, Moller $\mathrm{AB}$, et al. (2012). National, regional, and worldwide estimates of preterm birth rates in the year 2010 with time trends since 1990 for selected countries: a systematic analysis and implications. Lancet. 2012 Jun 9; 379 (9832): 2162-72. doi: $10.1016 / \mathrm{S} 0140-6736$ (12) 60820-4.

[3] Furdon A. s., Rosenkrantz T., Clark D. and Windle M. (2014). Prematurity Clinical Presentation. http://emedicine.medscape.com/article/975909-clinical.

[4] Hassanein, S (2011). Autologous Umbilical Cord Blood Transfusion for Preterm Neonates. Ain Shams University, Medical School. Cairo, Egypt.

[5] Lawn J. E., Davidge R., Paul V., Xylander S., Johnson J. D., Costello A., Kinney M, Segre M. and Molyneux L. (2012).
Chapter 5: Care for the preterm baby www.who.int/pmnch/media/news/2012/borntoosoon_chapter5 .pdf

[6] Simons SH, van Dijk M, van Lingen RA et al. Do we still hurt newborn babies? A prospective study of procedural pain and analgesia in neonates. Arch Pediatr Adolesc Med 2003; 157 (11): 1058-64.

[7] Gibbins S, Maddalena P, Moulsdale W, et al. Pain assessment and pharmacologic management for infants with NEC: a retrospective chart audit. Neonatal Netw. 2006; 25: 339-345.

[8] Stevens B, Yamada J, Lee Y G., Ohlsson A. Sucrose for analgesia in newborn infants undergoing painful procedures. Cochrane Database of Systematic Reviews 2013, Issue 1. Art. No.: CD001069. DOI: 10.1002/14651858.CD001069.pub4.

[9] American Academy of Pediatrics (the Committee on Fetus and Newborn; Committee on Drugs; Section on Anesthesiology; and Section on Surgery), Canadian Paediatric Society (the Fetus and Newborn Committee). Prevention and management of pain and stress in the newborn infant. Pediatrics 2000; 105: 454-61.

[10] Anand KJ; International Evidence-Based Group for Neonatal Pain. Consensus statement for the prevention and management of pain in the newborn. Archives of Pediatrics and Adolescent Medicine 2001; 155: 173-80.

[11] Anand KJS, Stevens BJ, McGrath PJ. Future direction for clinical research in infancy. In: Pain in Neonates and Infants. Amsterdam: Elsevier, 2007: 299-309.

[12] Carbajal R, Rousset A, Danan C, Coquery S, Nolent P, Ducrocq $S$, et al. Epidemiology and treatment of painful procedures in neonates in intensive care units. Journal of the American Medical Association 2008; 300: 60-70.

[13] Anand KJ, Scalzo FM. Can adverse neonatal experiences alter brain development and subsequent behavior? Biol Neonate. 2000; 77: 69-82

[14] Walden M., Gibbins S. (2008). Pain Assessment and Management, Guideline for practice; $2^{\text {nd }}$ edition.

[15] McGrath JM, Braescu AV. State of the science: feeding readiness in the preterm infant. J Perinat Neonatal Nurs. 2004 Oct-Dec; 18 (4): 353-68; quiz 369-70.

[16] Hatifield N. (2003). Bro Adribb's Introductory Pediatric Nursing. $6^{\text {th }}$ ed., Lippincot Williams and Wilkins. Philadelphia. Chapter 15, Pp 320-322.

[17] Allen, T. (2009). Massage for Growth \& Development. Retrived May 20, 2010 from http://www.info@liddlekidz.com

[18] Anand, D., Kantak, M. \& John T. (2009). Respiratory Distress Syndrome in Neonates. Retrieved June 7, 2010 from http://www.merck.com/mmpe/sec19/ch277/ch277a.html.

[19] Johnston CC, Sherrard A, Stevens B, Franck L, Stremler R, Jack A. Do cry features reflect pain intensity in preterm neonates? A preliminary study. Biol Neonate. 1999; 76: 120 124

[20] B. Stevens, C. Johnston, L. Franck, P. Petryshen, A. Jack, and G. Foster, "The efficacy of developmentally sensitive interventions and sucrose for relieving procedural pain in very low birth weight neonates," Nursing Research, vol. 48, no. 1, pp. 35-43, 1999. 
[21] Gibbins S, Stevens B, Hodnett E, Pinelli J, Ohlsson A, Darlington G. Efficacy and safety of sucrose for procedural pain relief in preterm and term neonates. Nurs Res. 2002; 51: 375-82.

[22] Slater R, Worley A, Fabrizi L, et al. Evoked potentials generated by noxious stimulation in the human infant brain. Eur J Pain. 2010; 14: 321-326.

[23] Harrison D, Beggs S, Stevens B. Sucrose for procedural pain management in infants. Pediatrics. 2012; 130: 918-925. doi: 10.1542/peds. 2011-3848

[24] Acharya AB, Annamali S, Taub NA, Field D. Oral sucrose analgesia for preterm infant venepuncture. Arch Dis Child Fetal Neonatal Ed. 2004; 89: F 17-F 18.
[25] Gray L, Watt L, Blass EM. Skin-to-skin contact is analgesic in healthy newborns. Pediatrics 2000 Jan; 105: e 14

[26] Firoozeh Sajedi, Zahra Kashaninia, Mehdi Rahgozar, Fariba Asadi Noghabi. (2007). The Effect of Kangaroo Care on Physiologic Responses to Pain of an Intramuscular Injection in Neonates. Iranian Journal of Pediatrics, http://ijp.tums.ac.ir/index.php/ijp CrossRefMedlineWeb of Science.

[27] Johnston CC, Filion F, Campbell-Yeo M, Goulet C, Bell L, McNaughton K, Byron J, Aita M, Finley GA, Walker CD. Kangaroo mother care diminishes pain from heel lance in very preterm neonates: a crossover trial. BMC Pediatr. 2008 Apr 24; 8: 13. doi: 10.1186/1471-2431-8-13. 